Article

\title{
Effects of Increasing Feed Rate on Tool Deterioration and Cutting Force during End Milling of 718Plus Superalloy Using Cemented Tungsten Carbide Tool
}

\author{
Nurul H. Razak ${ }^{\dagger}$, Zhan W. Chen * and Timotius Pasang \\ Department of Mechanical Engineering, Auckland University of Technology, Auckland 1010, New Zealand; \\ hidayahrazak@ump.edu.my (N.H.R.); tpasang@aut.ac.nz (T.P.) \\ * Correspondence: zhan.chen@aut.ac.nz; Tel.: +64-09-921-9999 \\ + Current address: Faculty of Manufacturing, Universiti Malaysia Pahang, 26600 Pekan, Malaysia.
}

Received: 30 September 2017; Accepted: 17 October 2017; Published: 19 October 2017

\begin{abstract}
Understanding how feed rate $\left(f_{t}\right)$ affects tool deterioration during milling of Ni-based superalloys is practically important, but this understanding is currently insufficient. In the present study using a 718Plus Ni-based alloy and cemented tungsten carbide tool inserts, milling experiments were conducted with $f_{\mathrm{t}}=0.10 \mathrm{~mm} /$ tooth under either dry or wet (with coolant) conditions. The results are compared to those based on using $f_{\mathrm{t}}=0.05 \mathrm{~mm} /$ tooth from previous studies. The milling force $(F)$ was monitored, the cutting tool edge was examined and the flank wear $\left(V B_{\max }\right)$ was measured. As would be expected, an increase in $f_{\mathrm{t}}$ increased $F$. It was found that $F$ correlated well with $V B_{\max }$ for the high $f_{\mathrm{t}}(0.1 \mathrm{~mm} /$ tooth $)$ experiments, as opposed to the previously observed poor $F-V B_{\max }$ relationship for the lower $f_{\mathrm{t}}(0.05 \mathrm{~mm} /$ tooth $)$ value. This is explained, supported by detailed failure analysis of the cutting tool edges, by the deterioration mode to be dominantly edge chipping with a low occurrence of fracturing along the flank face when the high $f_{\mathrm{t}}$ was used. This dominancy of the deterioration mode means that the tool edge and workpiece contact was consistent and thus resulted in a clear $F-V B_{\max }$ relationship. A clear $F-V B_{\max }$ relationship should then mean monitoring $V B_{\max }$ through monitoring $F$ is possible.
\end{abstract}

Keywords: Ni-superalloy; tool deterioration; cutting force; wear monitoring

\section{Introduction}

Nickel-based superalloys are very important for applications in the aerospace industry, as they have excellent mechanical properties and creep resistance at high temperatures. However, primarily as a result of their excellent mechanical strength, which thus results in a high cutting force during machining and readily causes tool failure, nickel-based alloys are also difficult-to-cut materials. Milling, which is a basic machining process, is routinely used for material removal and final surface finish, and cemented tungsten carbide (WC-Co) tools are commonly used for milling nickel-based superalloys. Tool deterioration during machining and thus a short tool life have severe and negative effects on the surface integrity [1] and cost [2]. A shortened tool life also has a significant and negative effect on the environment, as the embedded energy associated with WC-Co tools is reasonably high [3]. Thus, the machinability of nickel-based superalloys focusing on tool deterioration mechanisms and tool life has long been the subject of a strong research effort and has been reviewed fairly comprehensively [4-6].

A number of studies [7-10] have shown that the chipping and breakage of the tool are the major failure modes during machining, including milling, of nickel-based superalloys using WC-Co tools. The progression of tool failure during the milling of a nickel-based superalloy (718Plus), using an ordinary milling condition, has been characterised and explained [11]. The deterioration starts as tool edge chipping and microcrack initiation in the edge of the rake's face side. The tool life based on a 
flank wear $\left(V B_{\max }\right)$ measurement can then be reached by the continuation of severe edge chipping or by fracturing with crack propagation in the subsurface region along the flank face. The gradual loss of edge material resulting in edge wear was also observable. The milling force $(F)$ corresponds to each major mode of deterioration differently and thus the overall correlation of $F-V B_{\max }$ has been found to be poor [12]. The poor $F-V B_{\max }$ relationship has been attributed to the measurement of tool deterioration (wear) based on flank wear, as the measurement does not take into account the change of edge geometry. The latter affects $F$ significantly.

In the milling of nickel-based superalloys, feed rate, defined as the forward distance per tooth in each revolution $\left(f_{\mathrm{t}}\right)$, is generally low, but the values used in various studies vary considerably, ranging from 0.0075 to $0.2 \mathrm{~mm} /$ tooth $[7,8,13-19]$. It has been suggested that $f_{\mathrm{t}}$ is a dominant factor for tool life and that lowering $f_{\mathrm{t}}$ may increase the tool life [14,17], although the tool life taking into account material removal has not been well clarified. Whether the variation of $f_{\mathrm{t}}$ may affect the mode of tool failure has not been considered. The modes of tool deterioration [11] and how the progression of tool deterioration affects $F$ [12], explained for end milling of a nickel-based superalloy, have been based on a $f_{\mathrm{t}}$ value of $0.05 \mathrm{~mm} /$ tooth. This value appears to be (or to be close to) the most commonly used value in nickel-based superalloy milling research [7,8,13-19]. As has been explained [12], using $f_{\mathrm{t}}$ of $0.05 \mathrm{~mm} /$ tooth, the edge radius of even the new tools is approximately the same as the un-cut chip thickness. An illustration of the radius $(r 1)$ comparable to the effective depth of the cut $\left(d_{\mathrm{c} 0.05}\right)$ is shown in Figure 1 (mid-schematic). For the small $f_{\mathrm{t}}(0.05 \mathrm{~mm} /$ tooth) value, the effective rake angle may be treated as negative. During machining, a slight wear of the cutting edge may further increase the effective radius, and ploughing may become significant. Figure 1 also suggests that by doubling $f_{\mathrm{t}}$ to $0.1 \mathrm{~mm} /$ tooth, the effect of the cutting edge radius on the effective rake angle may significantly reduce.
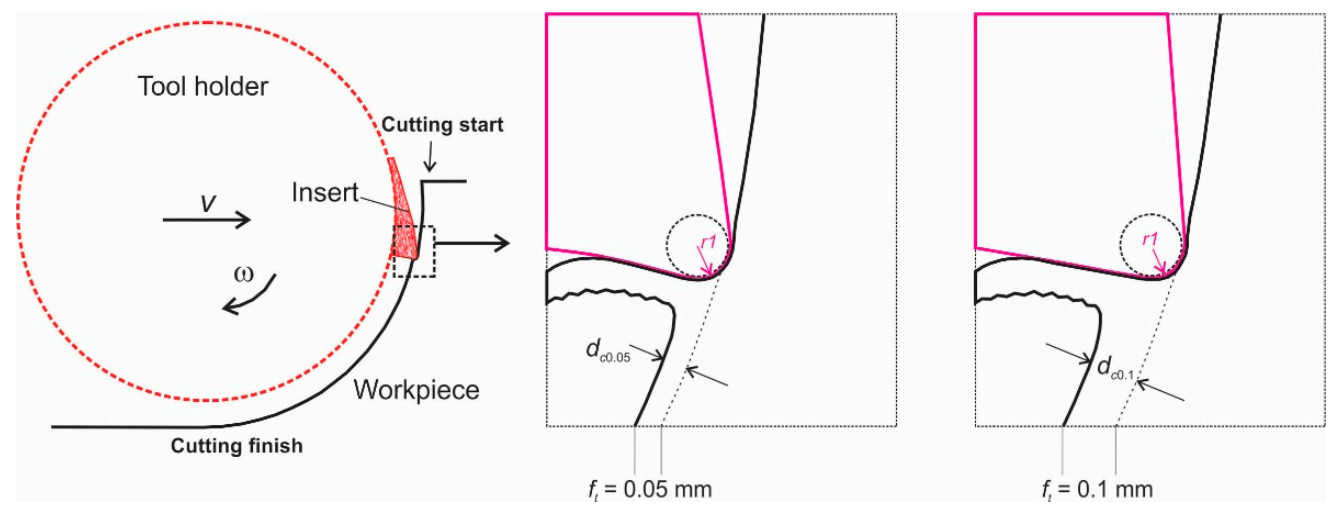

Figure 1. Schematic illustration of milling with two feed rate values: $0.05 \mathrm{~mm}$ and $0.1 \mathrm{~mm}$.

How tools perform by increasing the effective un-cut chip thickness through the increase of $f_{\mathrm{t}}$ may thus be worthwhile to be explained. This is because increasing $f_{\mathrm{t}}$ means increasing the production rate, but the effects of increasing $f_{\mathrm{t}}$ on tool deterioration and on $F$ need to be better understood. Thus, in the present study, down-milling experiments using a nickel-based alloy and WC-Co tool have been conducted to aid in understanding how increasing $f_{\mathrm{t}}$ may affect tool deterioration. A high $f_{\mathrm{t}}$ value was used, and this value was twice as high as the commonly viewed low-medium $f_{\mathrm{t}}$ value used in the previous study [12]. During either dry milling experiments or milling using a coolant, $F$ was monitored. The cutting tool edge was examined and $V B_{\max }$ was measured after each milling pass. Through these experiments and examination/measurement, how increasing the $f_{\mathrm{t}}$ value affects the mode and rate of tool deterioration and $F$ could be studied and better understood. Furthermore, interrupting experiments were also conducted so that the deformation zone under the different milling conditions could be evaluated. This was in order to provide information on how the use of the coolant to cool the workpiece may affect tool deterioration and the cutting force, using the two different $f_{\mathrm{t}}$ values. 


\section{Experimental Procedures}

The same Ni-based alloy as used in our earlier studies [11,12] was used in the present study: Superalloy 718Plus. Its compositional specification is given in Table 1. The as-received bar (76 $\mathrm{mm}$ in diameter) was in an annealed state with hardness values of 30-31 HRC. Workpieces were machined out from the as-received bar. The dimensional details were given previously [11,12], and the top milling surface area of the workpiece was $60 \times 43 \mathrm{~mm}^{2}$. Thus a milling pass was $60 \mathrm{~mm}$. A tool holder can hold two tool inserts, but the single insert arrangement was used so that the monitoring of the deterioration of each tool was unambiguous. The radius of the tool holder/insert, the distance between the cutting edge of the insert to the centre of the tool holder, was $16 \mathrm{~mm}$. The tool insert material was cemented tungsten carbide, WC, with 12.5\% Co binder (APKR 1003PDR-H IC 28 uncoated inserts from ISCAR). Two milling experiments were conducted without $\left(\mathrm{Tool}_{\mathrm{dry} 1}\right.$ and $\left.\mathrm{Tool}_{\mathrm{dry} 2}\right)$ and two were conducted with using coolant $\left(\right.$ Tool $_{\text {wet1 }}$ and Tool $_{\text {wet2 }}$ ). For wet milling, coolant (HOCUT 795B; from Houghton, Australia; 1:10 to-water ratio) with a flow rate set at $0.02 \mathrm{~L} / \mathrm{s}$ through the nozzle was directed to the milling location.

Table 1. Composition specification of 718Plus (wt \%).

\begin{tabular}{cccccccccccccc}
\hline $\mathbf{N i}$ & $\mathbf{C r}$ & $\mathbf{F e}$ & $\mathbf{C o}$ & $\mathbf{N b}$ & $\mathbf{M o}$ & $\mathbf{W}$ & $\mathbf{T i}$ & $\mathbf{A l}$ & $\mathbf{S i}$ & $\mathbf{M n}$ & $\mathbf{C u}$ & $\mathbf{C}$ & Others \\
\hline Bal & $19-21$ & $8-10$ & $8-10$ & $5.2-5.8$ & $2.5-3.1$ & $0.8-1.4$ & $0.5-1.0$ & $1.2-1.7$ & $0-0.35$ & $0-0.35$ & 0.3 & $0.01-0.05$ & $<0.035$ \\
\hline
\end{tabular}

As explained previously [11,12], a basic condition that could be regarded as "ordinary" for milling nickel-based superalloys is the following: the rotation speed $(1000 \mathrm{rpm})$ and forward speed $(50 \mathrm{~mm} / \mathrm{min})$ of the milling machine to obtain the cutting speed $\left(v_{\mathrm{c}}\right)$ of $50 \mathrm{~m} / \mathrm{min}$ and $f_{\mathrm{t}}=0.05 \mathrm{~mm} / \mathrm{rev}$. The depth of cut (DOC) of $0.5 \mathrm{~mm}$ and the radial depth of cut $\left(a_{\mathrm{e}}\right)$ of $9.0 \mathrm{~mm}$ were used. In the present $f_{\mathrm{t}}$ comparative experiments, $f_{\mathrm{t}}$ was increased to $0.1 \mathrm{~mm} / \mathrm{rev}$, and the tool performance and milling force were compared to those reported previously for $f_{\mathrm{t}}=0.05 \mathrm{~mm} / \mathrm{rev}$. During milling, forces in feed $\left(F_{\mathrm{f}}\right)$ and normal to feed $\left(F_{\mathrm{fN}}\right)$ directions in the working plane and in the direction normal to the working plane $\left(F_{\mathrm{p}}\right)$, as designated in the ISO 3002/4 [20], were measured using a Kistler dynamometer. The milling force is then

$$
F=\sqrt{F_{\mathrm{f}}^{2}+F_{\mathrm{fN}}^{2}+F_{\mathrm{p}}^{2}}
$$

The sampling rate was set at $1000 / \mathrm{s}$. Because each milling cycle (revolution) took $0.06 \mathrm{~s}(60 / 1000 \mathrm{~s} / \mathrm{rev})$, there were $60(1000 / \mathrm{s} \times 0.06 \mathrm{~s})$ force data points in each cycle.

For each tool insert/experiment, after each milling pass, the insert was removed from the tool holder and examined using a Hitachi SU-70 field emission scanning electron microscope (SEM) (Hitachi High-Technologies, Tokyo, Japan) before the next milling pass. The positioning of inserts in the SEM sample holder was as consistent as possible, for viewing on the side flank face, the bottom flank face and the rake face. The details of this viewing have been explained previously [11], and through this viewing, how a tool cutting edge has deteriorated can be properly assessed. The flank wear $\left(V B_{\max }\right)$ measurement was based on the common method following ISO Standard 8688-2 [21]. In our work, an outline of the cutting edge was first made on the basis of the SEM image of the tool insert before milling (zero pass). This zero pass edge outline (ZPEO) was fit/placed onto each subsequent pass insert's edge SEM image. In this way, $V B_{\max }$ could be directly measured. This practice based on SEM images enables what is specified in the standard to be followed.

As already explained, included in the present study were interruption milling experiments. In these experiments, the machine bed was suddenly reversed when milling had been advanced for about $30 \mathrm{~mm}$. Hence, a zone of hardness change in the workpiece ahead of the cutting tool edge could be preserved. For sampling of the workpiece, a sample (A- $\left.\mathrm{A}^{\prime}\right)$ was sectioned out, as shown in Figure $2 a$, using wire cutting. The sectioned sample was mounted and polished for a microhardness measurement conducted using a Vicker microhardness tester with $50 \mathrm{gf}$ loading for $10 \mathrm{~s}$. Figure $2 \mathrm{~b}$ is 
an image of hardness indentations on a sample around the milled front. The use of a low load, for which indentation could still be accurately measured, is for enabling hardness to be measured close to the milled surface. From the measured values, a hardness map can be constructed. In a distance away from the milled front of the workpiece, hardness values should be approximately $310 \mathrm{HV}$ (hardness of the as-received workpiece). Towards the milled front, the workpiece material has been deformed during milling and thus work-hardened. A hardness map can thus provide information on the size of the deformation zone during milling.

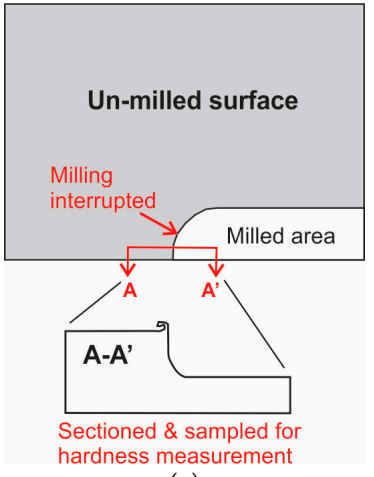

(a)

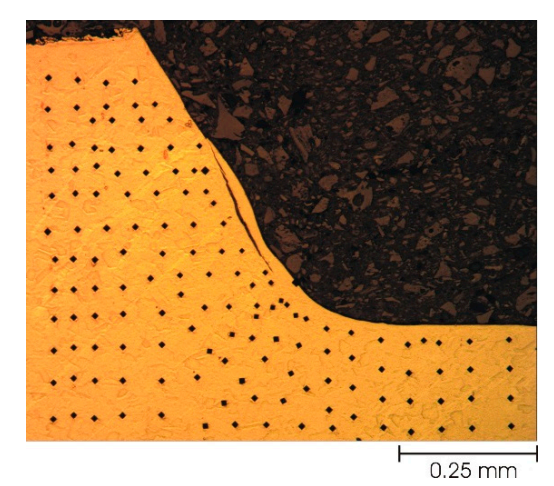

(b)

Figure 2. Illustration of metallographic sample location from milling interrupted workpiece for hardness measurement: (a) schematic of workpiece viewing from top and sampled A- $\mathrm{A}^{\prime}$ cross section viewing from side, and (b) an area of an $\mathrm{A}-\mathrm{A}^{\prime}$ metallographically prepared sample with hardness indentations near the milled front.

\section{Results and Discussion}

\subsection{Mode and Progression of Tool Deterioration}

The effect of milling on the tool edge for each of the present four milling experiments using $f_{\mathrm{t}}=0.1 \mathrm{~mm} / \mathrm{rev}$ is presented one by one, starting with viewing the side flank face of Tool $\mathrm{dry}_{1}$ shown in Figure 3 for dry milling. The edge has been slightly affected after one pass, with $V B_{\max }=0.12 \mathrm{~mm}$, which includes the exposure of WC grains in the edge area and 718 build-up layer (BUL) behind, within the $0.5 \mathrm{~mm}$ DOC region. That the exposure is the result of edge wear, minor edge chipping and the BUL results from workpiece material extruded for a short distance behind the tool-workpiece contact has been demonstrated and explained [11]. Figure 3b-d shows that, in subsequent passes, tool deterioration has progressed gradually but has primarily been confined in the tool edge area. During milling using $f_{\mathrm{t}}=0.05 \mathrm{~mm} / \mathrm{rev}$, a deterioration mode characterised by heavy chipping, indicating fracturing of a thin piece a long distance along the flank face well beyond the edge area, was not uncommon $[11,12]$. This mode of deterioration did not occur in the milling experiment of this Tool $_{\text {dry } 1} \mathrm{using} f_{\mathrm{t}}=0.1 \mathrm{~mm} / \mathrm{rev}$.

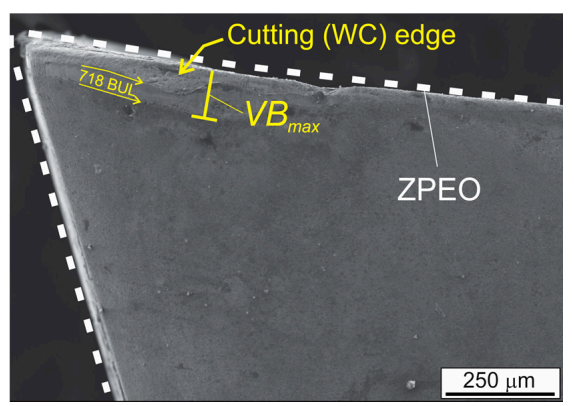

(a)

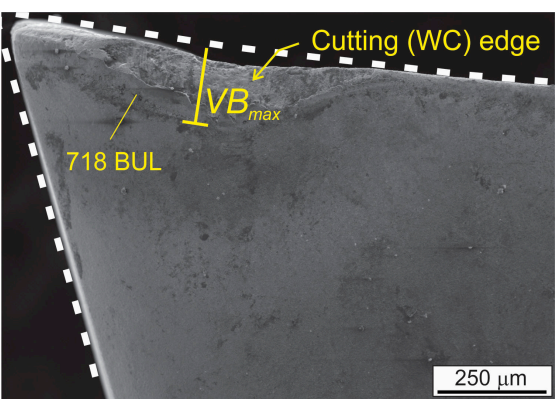

(b)

Figure 3. Cont. 


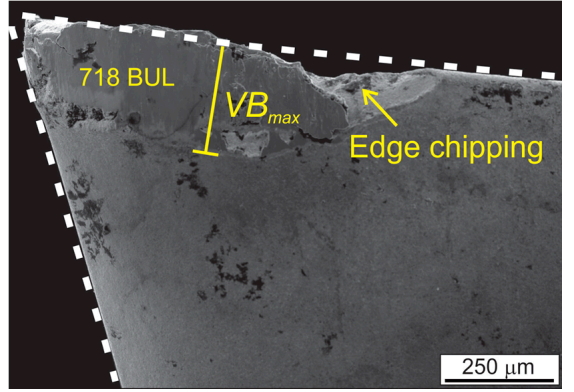

(c)

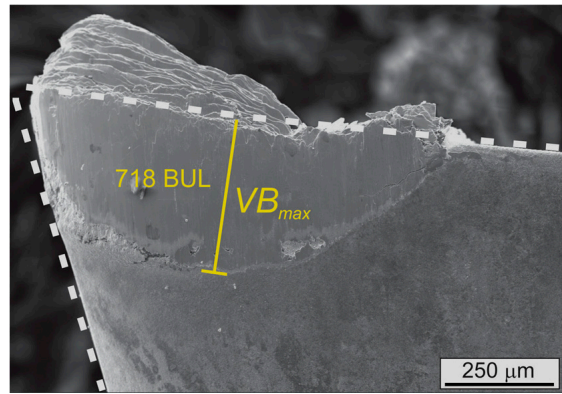

(d)

Figure 3. Scanning electron microscope (SEM) images of Tool ${ }_{\text {dry1 }}$ side flank face after various milling passes: (a) after the first pass, (b) after the second pass, (c) after the third pass, and (d) after the fourth pass. Zero pass edge outline (ZPEO) of the tool is placed in each image.

In Figure 4, SEM images of the bottom flank face and rake face for Tool $\mathrm{dry}_{1}$ after three and four passes are shown. These images confirm that the gradual loss of the tool material was mainly confined to the cutting edge/corner location where the tool and workpiece contacted during milling. The contact (cutting) area is where the tool forced the workpiece locally to deform and flow out as chips (workpiece material). This forcing during milling was also in the form of shearing/rubbing between the tool edge and the workpiece in the tertiary shear zone. This rubbed/smeared workpiece material stuck on the cutting edge as the BUL accompanying the wear and chipping confined in the cutting edge is thus expected. It can also be expected that, as the cutting edge deteriorates and blunts more severely, a larger shearing/rubbing area and thus coverage of a larger area by the BUL should result. Figure $3 \mathrm{~d}$ and particularly Figure $4 \mathrm{~b}$ demonstrate this.
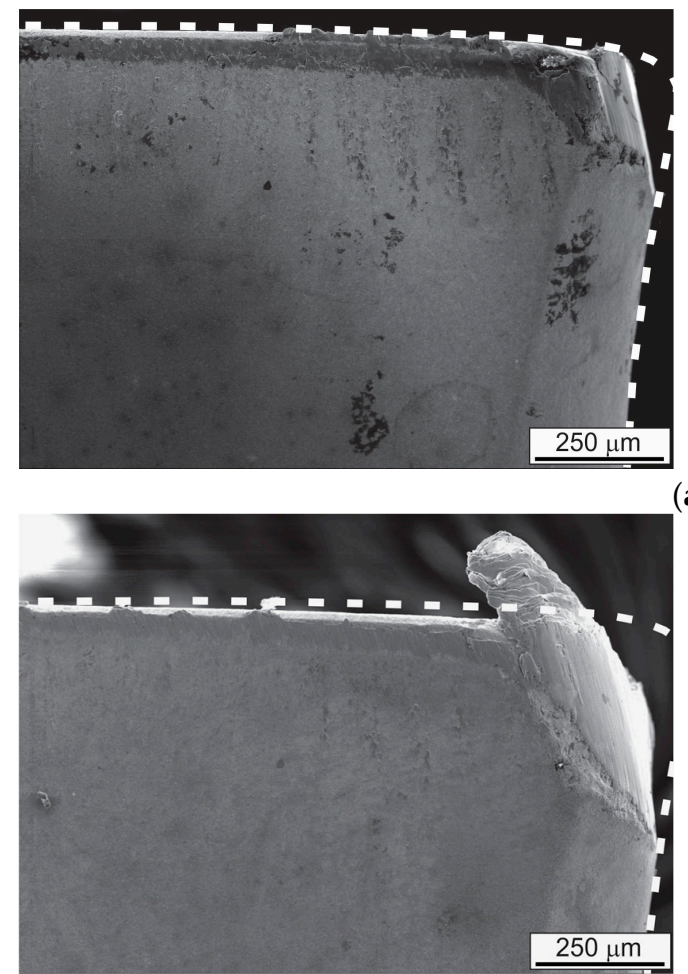

(a)
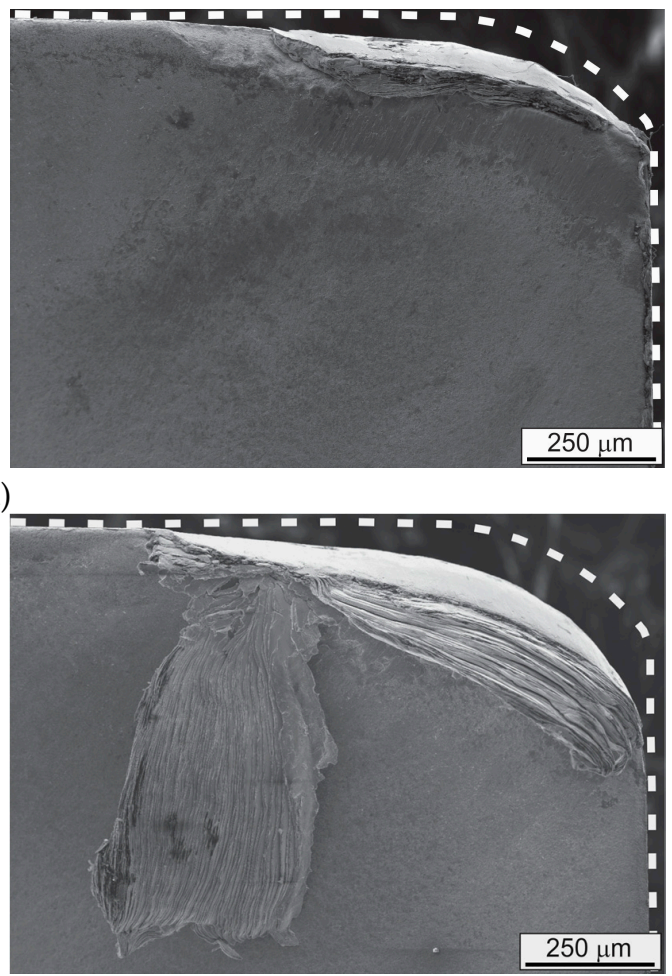

(b)

Figure 4. Scanning electron microscope (SEM) images of Tool dry 1 bottom flank face on the left and rake face on the right, with zero pass edge outline (ZPEO): (a) after the third pass, and (b) after the fourth pass. 
Compared to the insert before milling shown by ZPEO, the edge viewed on the bottom flank face and rake face of the tool in Figure $4 \mathrm{~b}$ clearly shows that severe blunting has taken place. For this reason, no further milling was conducted for this tool. The amount of tool edge material loss causing the blunting is quite clear from viewing these two faces (bottom flank and rake), rather than measuring $V B$ on the basis of viewing the side flank face, which is the conventional method as specified in ISO Standard 8688-2 [21]. Viewing the side flank face, $V B_{\max }=0.36 \mathrm{~mm}$ could be measured for Tool ${ }_{\text {dry } 1}$ after the fourth pass (Figure 3d). Although this value does not contain the true geometrical and volumetric information on the actual amount of deterioration, it indirectly indicates the severity of the deterioration that can be more directly observed by viewing the bottom face and the rake face.

Side flank face images of the tool after the second and third pass in the second dry milling experiment using Tool $_{\mathrm{dry} 2}$ are shown in Figure 5. The mode of deterioration, rather than the rate, being confined to the cutting edge for this second experiment, was the same as that in the first $\left(\operatorname{Tool}_{\mathrm{dry} 1}\right)$, as explained above. Edge chipping (notching) has been more markedly revealed in Figure 5. However, in general, edge chipping may not be clearly viewed constantly, as it may depend on the amount of BUL or other forms of build-up material on the edge area. As shown in Figure $4 b$, after three passes, $V B_{\max }=0.35 \mathrm{~mm}$ for this second dry milling experiment. This value was comparable to the value after four passes in the first dry milling experiment, for which it has been explained that the tool $\left(\mathrm{Tool}_{\mathrm{dry} 1}\right)$ should be viewed as severely deteriorated. Thus, this second dry milling experiment for Tool $\mathrm{dry}_{2}$ stopped after three passes.

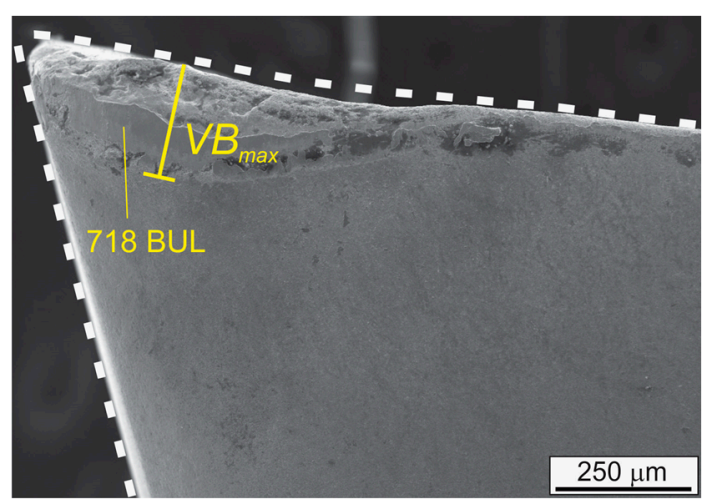

(a)

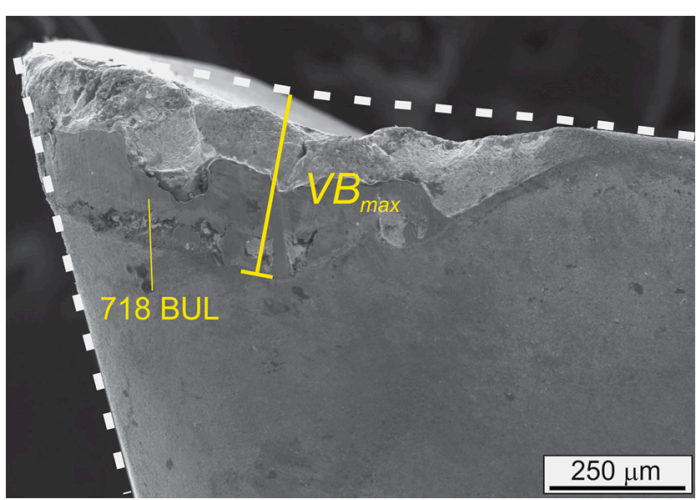

(b)

Figure 5. Scanning electron microscope (SEM) images of Tool $\mathrm{dry}_{2}$ side flank face with zero pass edge outline (ZPEO): (a) after the third pass, and (b) after the fourth pass.

Side flank face images of $\mathrm{Tool}_{\text {wet2 }}$ for the milling experiment using coolant (wet milling) are shown in Figure 5. As can be seen in Figure 5a, after the first three passes, $V B_{\max }$ was $0.24 \mathrm{~mm}$. This was comparable to that measured for the Tool $\mathrm{dry}_{1}$ after dry milling for three passes, as shown in Figure 2c. In the next (fourth) pass in this wet milling experiment, the tool deterioration accelerated and $V B_{\max }$ $(0.64 \mathrm{~mm})$ increased considerably. However, as is seen in Figure $6 \mathrm{~b}$, the mode of deterioration remained the same, meaning that the severe deterioration had essentially been the blunting of the edge/corner without fracturing long pieces along the flank face outside of the contact area of cutting. In comparison to the two dry milling experiments, this first wet milling experiment thus did not demonstrate a positive effect of using coolant on the tool life. 


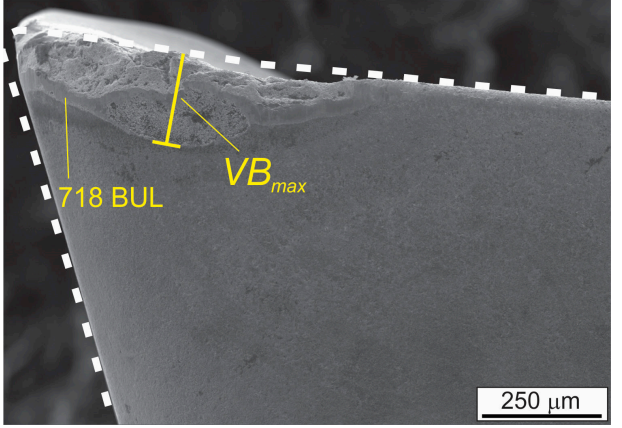

(a)

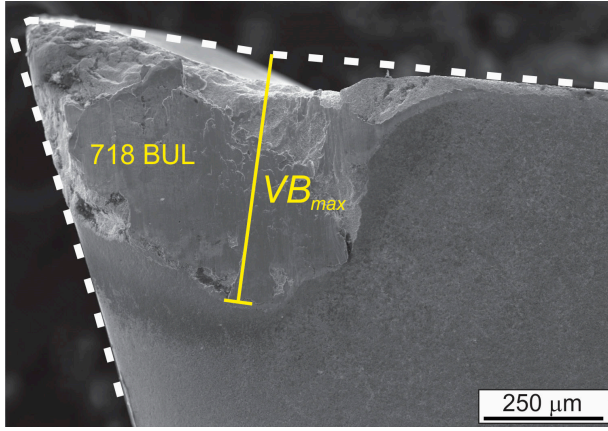

(b)

Figure 6. Scanning electron microscope (SEM) images of Tool ${ }_{\text {wet1 }}$ side flank face with zero pass edge outline (ZPEO): (a) after the third pass, and (b) after the fourth pass.

In comparison to the first wet milling experiment, in the second wet milling experiment using $\mathrm{Tool}_{\mathrm{wet} 2}$, an increased rate of the tool deterioration was observed. This can been seen by comparing the side flank face images in Figure 7 to those in Figure 6. After two passes (Figure 7a), $V B_{\max }$ was close to $0.3 \mathrm{~mm}$, which was the highest value after the same number of passes in all experiments. The mode of deterioration was still dominantly edge chipping. However, in the next (third) pass, as shown in Figure $7 \mathrm{~b}$, evidence of fracturing along the flank face with a thin layer coming off was observed. The $V B_{\max }$ value became high (close to $1 \mathrm{~mm}$ ). However, it is also evident that during the same pass, edge chipping was also very severe, and the $V B$ value for edge chipping may be observed to have been only slightly less than the $V B_{\max }$.

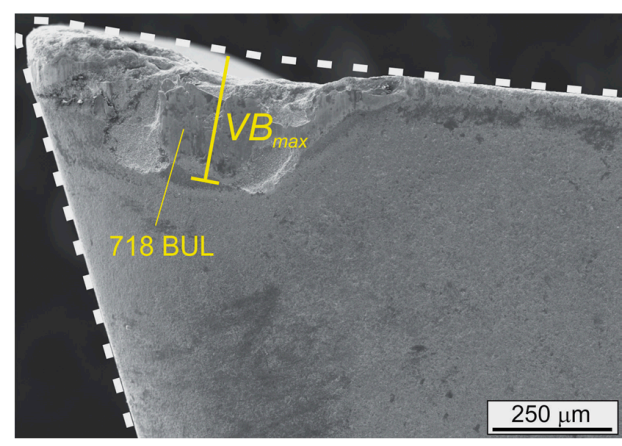

(a)

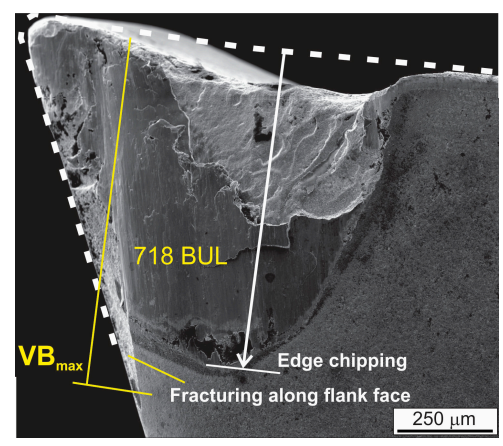

(b)

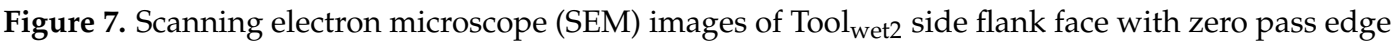
outline (ZPEO): (a) after the second pass, and (b) after the third pass.

Figure 8 is a summary plot of $V B_{\max }$ versus the number of passes $\left(N_{\text {pass }}\right)$ to indicate the progression of the tool deterioration for milling using $f_{\mathrm{t}}=0.1 \mathrm{~mm} / \mathrm{rev}$. As explained above, edge wear and edge chipping are the dominant modes of tool deterioration, which cause a gradual loss of the tool material in the cutting edge and thus a gradual blunting during the early passes. For the two wet milling experiments, the gradual blunting transiting to rapid blunting may be seen to have taken place in two to three passes. For the two dry milling experiments, the deterioration was considered severe, and thus no further passes were made after three $\mathrm{Tool}_{\mathrm{dry} 1}$ and four $\mathrm{Tool}_{\mathrm{dry} 2}$ passes. However, a considerable increase in $V B_{\max }$ may have been expected if a further pass was made to each of the dry milling experiments. Thus, for all four experiments, the transition may appear to have taken place after 2-4 passes for $f_{\mathrm{t}}=0.1 \mathrm{~mm} / \mathrm{rev}$. For $f_{\mathrm{t}}=0.05 \mathrm{~mm} / \mathrm{rev}$, the number of passes before the transition ranged from one to five [12]. Taking into account that doubling $f_{\mathrm{t}}$ halves the milling time for the same volume of material removal, the use of the higher $f_{\mathrm{t}}$ value for milling may result in a higher production rate without increasing the tool cost. 


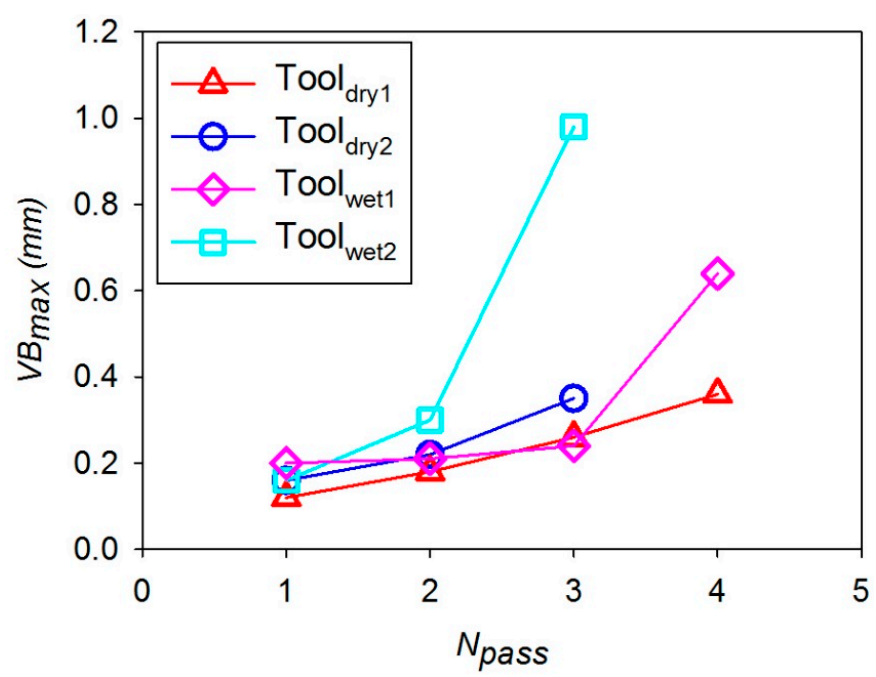

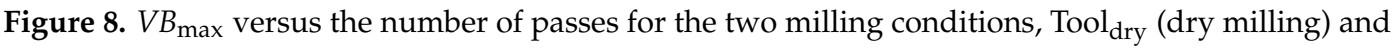
Tool $_{\text {wet }}$ (wet milling), for $f_{\mathrm{t}}=0.1 \mathrm{~mm} / \mathrm{rev}$.

\subsection{Cutting Force Relating to Tool Deterioration}

Figure 9 provides force data for two passes, the first pass and the third pass, from the same tool $\left(T_{0 o l_{\text {dry2 }}}\right.$ ) experiment to illustrate the general features of the milling force when using $f_{\mathrm{t}}=0.1 \mathrm{~mm} / \mathrm{rev}$. Force features in the beginning of a milling experiment and force variation within each cycle $(0.06 \mathrm{~s})$ have been explained in detail in the previous study using the commonly used $f_{\mathrm{t}}$ value of $0.05 \mathrm{~mm} / \mathrm{rev}$ [12]. By increasing $f_{\mathrm{t}}$ to $0.1 \mathrm{~mm} / \mathrm{rev}$, for the first pass (Figure $9 \mathrm{a}$ ), $F_{\mathrm{f}}$ and $F_{\mathrm{fN}}$ were comparatively higher (than the values when $f_{\mathrm{t}}=0.05 \mathrm{~mm} / \mathrm{rev}$ was used [12]), but $F_{\mathrm{p}}$ was largely the same. As can be judged from Figure $9 \mathrm{a}$, the value of $F_{\mathrm{e}-\mathrm{m}}$ is $\sim 375 \mathrm{~N}$ when using $f_{\mathrm{t}}=0.1 \mathrm{~mm} / \mathrm{rev}$; this compares to $F_{\mathrm{e}-\mathrm{m}} \approx 200 \mathrm{~N}$ when using $f_{\mathrm{t}}=0.05 \mathrm{~mm} / \mathrm{rev}$ [12]. The higher $F_{\mathrm{f}}$ and $F_{\mathrm{fN}}$ and thus higher $F_{\mathrm{e}-\mathrm{m}}$ values when a higher $f_{\mathrm{t}}$ value was used were expected, as a larger milling zone should require a greater milling force. In the third pass (Figure $4 \mathrm{~b}$ ), the milling force increased significantly and $F_{\mathrm{e}-\mathrm{m}}=670 \mathrm{~N}$.
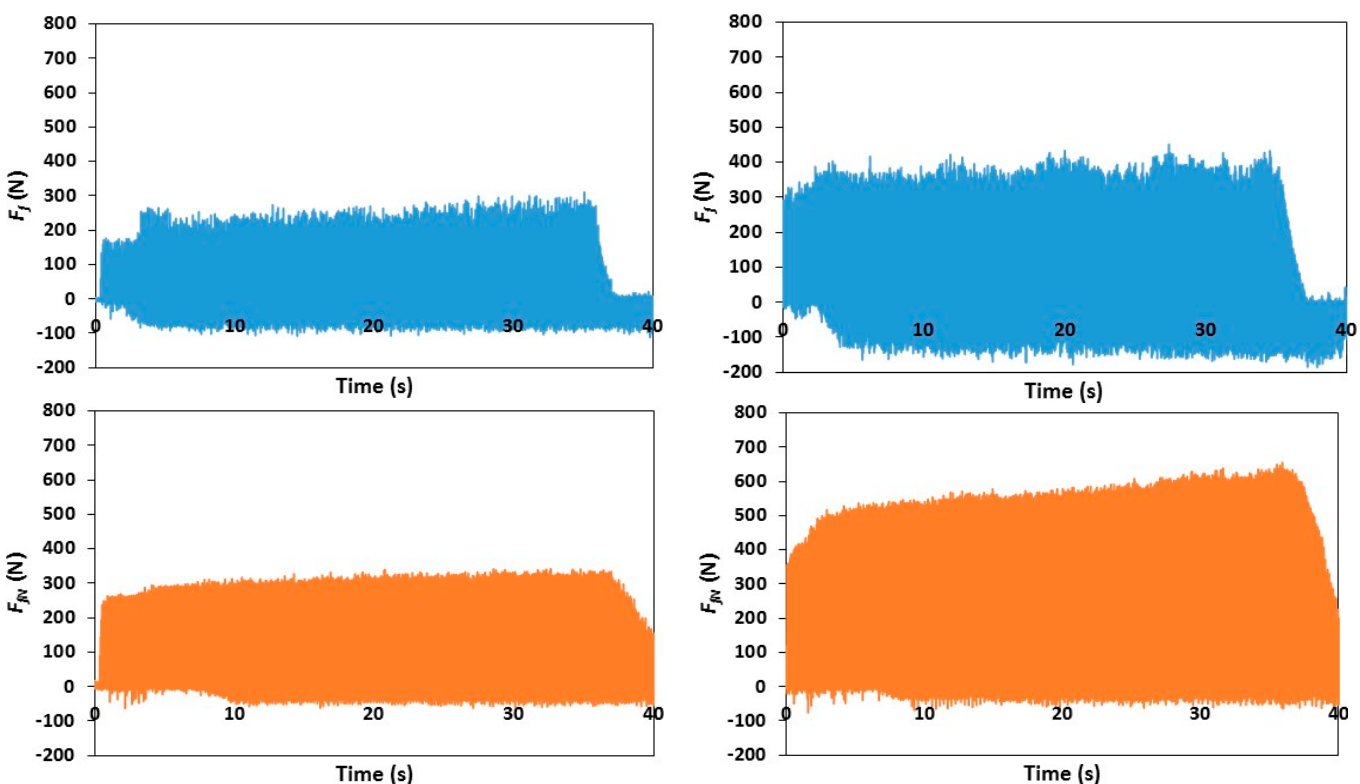

Figure 9. Cont. 

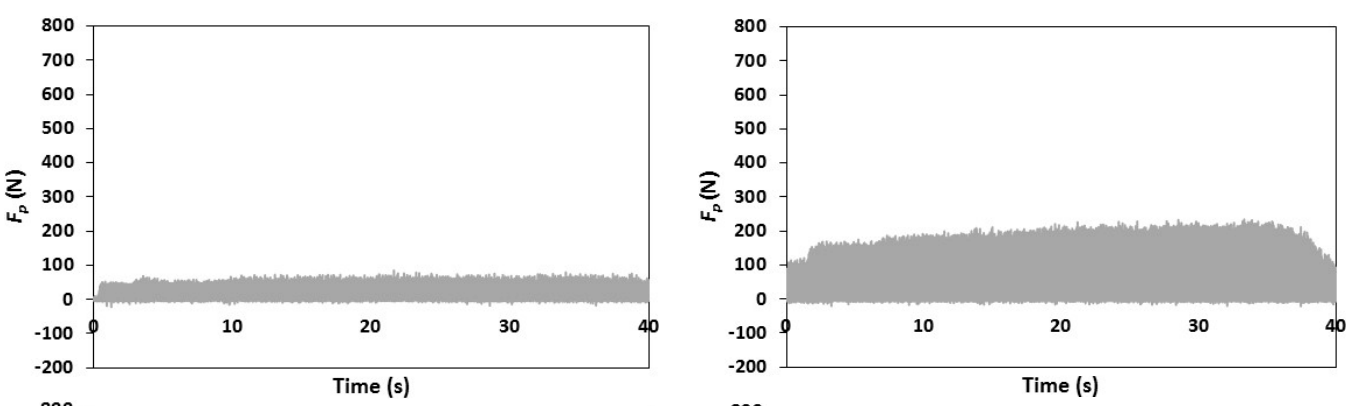

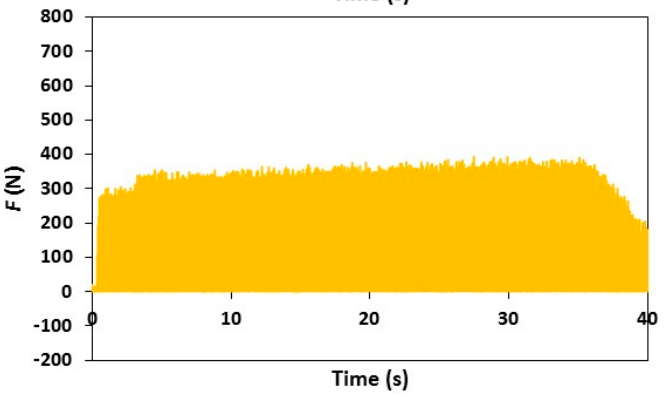

(a)

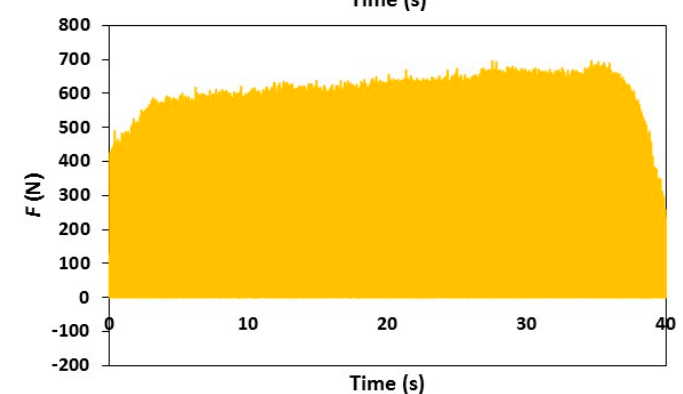

(b)

Figure 9. The whole $F_{\mathrm{f}}, F_{\mathrm{fN}}, F_{\mathrm{p}}$ and $F$ curves (recorded data) of Tool ${ }_{\mathrm{dry} 2}$ milling experiment: (a) during the first pass, and (b) during the third pass.

A clear indication shown in Figure 9 is that the milling force increased gradually within each pass. This indicates that the tool deterioration was confined to the cutting edge and progressed gradually. This is consistent with the observation on the tool edge as shown (Figure 5) and was explained for that experiment. As is shown in Figure 8,V $V B_{\max }$ increased slowly from $0.16 \mathrm{~mm}$ in the first pass to $0.22 \mathrm{~mm}$ in the second pass and $0.35 \mathrm{~mm}$ in the third pass. Thus, $\Delta V B_{\max }=0.19 \mathrm{~mm}$ corresponded to an increase of $F_{\mathrm{e}-\mathrm{m}}$ as can be seen in Figure 9 to be $275 \mathrm{~N}$, giving $\Delta F_{\mathrm{e}-\mathrm{m}} / \Delta V B_{\max }=275 \mathrm{~N} / 0.19 \mathrm{~mm}=1447 \mathrm{~N} / \mathrm{mm}$. In Figure 10, milling force data for the second and third pass of the tool $\left(\mathrm{Tool}_{\mathrm{wet} 2}\right)$ are shown. The most severe tool deterioration pass (Figure $7 \mathrm{~b}$ ) was accompanied by the rapid and rather irregular increase in the milling force (Figure 10b) in the pass. For this pass, $\Delta F_{\mathrm{e}-\mathrm{m}} / \Delta V B_{\max }=(1705-465) \mathrm{N} /(0.98-0.3) \mathrm{mm}=1824 \mathrm{~N} / \mathrm{mm}$. This was a higher rate than for Tool ${ }_{\mathrm{dry} 2}$.

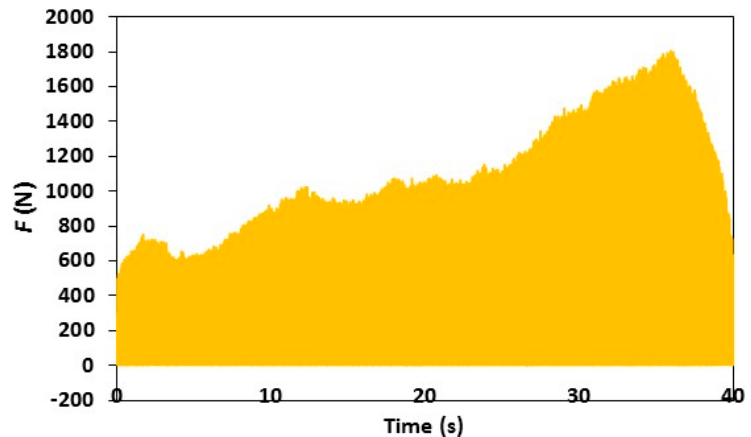

(a)

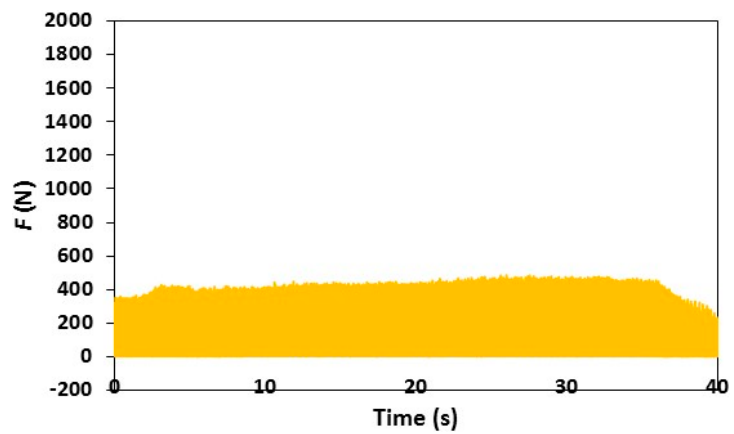

(b)

Figure 10. $F$ curves (recorded data) of Tool $_{\text {wet2 }}$ milling experiment during (a) the second pass, and (b) the third pass.

The rate of increase in $F_{\mathrm{e}-\mathrm{m}}$ as $V B_{\max }$ increased can be better examined by plotting $F_{\mathrm{e}-\mathrm{m}}$ as a function of $V B_{\max }$, as shown in Figure 11. Overall, $F_{\mathrm{e}-\mathrm{m}}$ increases almost linearly with $V B_{\max }$, where $\Delta F_{\mathrm{e}-\mathrm{m}} / \Delta V B_{\max }=1564 \mathrm{~N} / \mathrm{mm}$. This linearity for $f_{\mathrm{t}}=0.1 \mathrm{~mm} / \mathrm{rev}$ is very different to the poor 
$F_{\mathrm{e}-\mathrm{m}}-V B_{\max }$ relationship found for experiments using $f_{\mathrm{t}}=0.05 \mathrm{~mm} / \mathrm{rev}$. As has been explained [12], for $f_{\mathrm{t}}=0.05 \mathrm{~mm} / \mathrm{rev}, F_{\mathrm{e}-\mathrm{m}}-V B_{\max }$ values (from eight milling experiments) scatter widely, bound by the two $\mathrm{d} F_{\mathrm{e}-\mathrm{m}} / \mathrm{d} V B_{\max }$ curves, which are as plotted also in Figure 11 ; thus $F_{\mathrm{e}-\mathrm{m}}$ is poorly related to $V B_{\max }$. Data of $f_{\mathrm{t}}=0.1 \mathrm{~mm} / \mathrm{rev}$ in Figure 11 closely follow the higher-bound $\mathrm{d} F_{\mathrm{e}-\mathrm{m}} / \mathrm{d} V B_{\max }$ curve for $f_{\mathrm{t}}=0.05 \mathrm{~mm} / \mathrm{rev}$. As has also been explained [12], the upper-bound $\mathrm{d} F_{\mathrm{e}-\mathrm{m}} / \mathrm{d} V B_{\max }$ curve represents the deterioration mode of chipping and breakage confined to the cutting edge, blunting the edge as $N_{\text {pass }}$ increases. As has been demonstrated in Figures 4-7 and explained, this edge blunting mode is dominant for milling experiments using $f_{\mathrm{t}}=0.1 \mathrm{~mm} / \mathrm{rev}$, and thus $F_{\mathrm{e}-\mathrm{m}}-V B_{\max }$ data closely follow the high $\mathrm{d} F_{\mathrm{e}-\mathrm{m}} / \mathrm{d} V B_{\max }$ curve. The good correlation of $F_{\mathrm{e}-\mathrm{m}}-V B_{\max }$ serves as a base for monitoring tool deterioration using the milling force, which is an important method being developed for monitoring tool deterioration $[7,22,23]$.

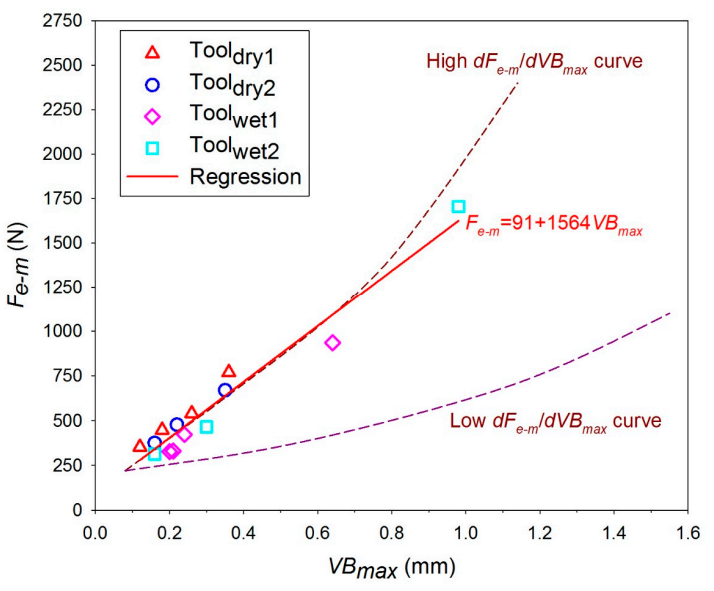

Figure 11. $F_{\mathrm{e}-\mathrm{m}}$ values versus $V B_{\max }$ for experiments conducted using $f_{\mathrm{t}}=0.1 \mathrm{~mm} / \mathrm{rev}$. The upper-bound (high) and lower-bound (low) $\mathrm{d} F_{\mathrm{e}-\mathrm{m}} / \mathrm{d} V B_{\max }$ curves for $f_{\mathrm{t}}=0.05 \mathrm{~mm} / \mathrm{rev}$ [12] are also plotted.

\subsection{Understanding the Effect of Coolant}

In the comprehensive review on tool wear during the machining of Ni-based superalloys, Zhu et al. [4] concluded that both cooling/lubrication and heating-assisted technologies may be used to control tool wear. The tribological and heat transfer information and explanation of the beneficial effects of either cooling or heating may however be seen as lacking. Shokrani et al. [24], also in a comprehensive review, discussed the role of coolants in the machining of difficult-to-machine materials, pointing to heat generated being the main issue. They further reason that cutting the temperature on which the hardness of the tool and the hardness of the workpiece both depend is the determining factor for machinability and thus tool life. However, detailed experimental data illustrating how an optimal temperature may be obtained for the improvement of the tool life during the milling of Ni-based alloys do not appear to be available.

As has often been suggested and as is clearly pointed out in the two reviews cited above [4,24], poor machinability, including poor tool life, of machining Ni-based alloys is the consequence of a high level of work hardening during cutting. However, mechanisms leading to softening should also occur depending on the temperatures during and post milling, as dry milling and wet milling can be viewed as two different thermal environments, and thus conditions for cutting heat to be conducted away should be different. This reasoning however is not consistent with the observation that the use of a coolant does not significantly affect the milling force. To understand this apparent contradiction, the degree of work hardening during the dry and wet milling experiments is briefly assessed. This is because experiments have already been conducted without (dry) and with (wet) the use of a coolant. Using the present interruption milling samples, as explained in the Experimental Procedures section and in Figure 2, maps of hardness distributions can be produced. 
Figure 12 shows hardness maps for experiments conducted using $f_{\mathrm{t}}=0.05 \mathrm{~mm} / \mathrm{rev}$. All the maps show a work hardened area ahead of the milled front/surface. For experiments using new tools (Tool $_{\text {dry3 }}$ and Tool $\left.{ }_{\text {wet3 }}\right)$, Figure 12a,b shows that the hardness increased from the 300-325 HV band to the $450-475 \mathrm{HV}$ band over a distance of about $0.20-0.25 \mathrm{~mm}$ towards the milled front in both the dry and wet milling experiments. It may be worthwhile to compare these values to the findings in the recent study on work hardening during the dry turning of Inconel 718 alloy by Ren and Liu [25]. In their study, the hardness increased from $\sim 380 \mathrm{HV}$ in the base material to 460-480 HV near the workpiece surface over a short work hardening distance. The workpiece hardness value was $\sim 380 \mathrm{HV}$ in their work, as their workpiece was in peak hardened state. The hardness values of our workpiece are within $300-325 \mathrm{HV}$, as the workpiece was in an annealed state. Work hardening resulted in hardness values that increased to the $450-470 \mathrm{HV}$ band towards the milled surface, which is comparable to the $460-480$ HV values in Ren and Liu's study.

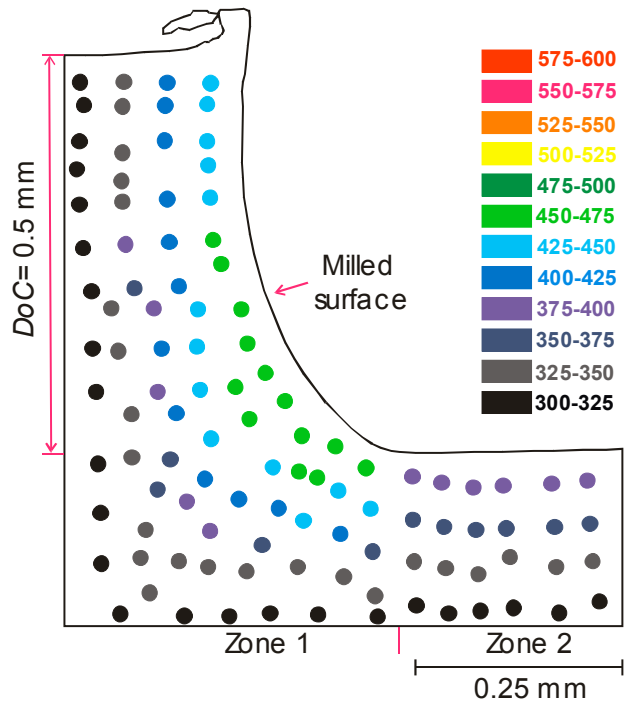

(a)

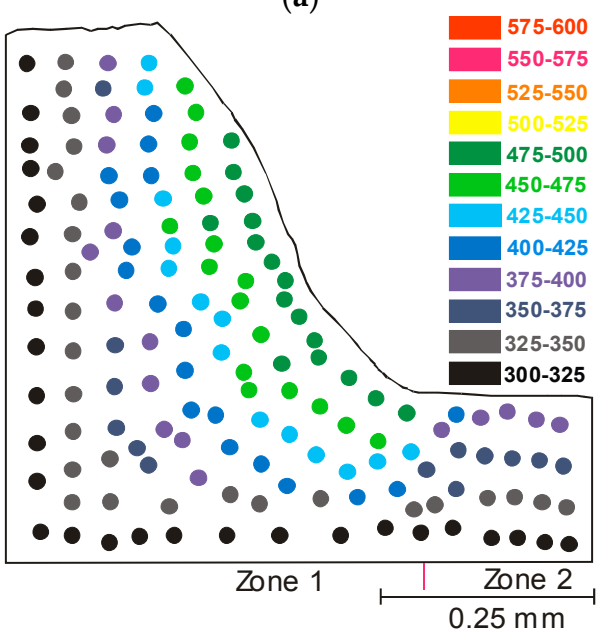

(c)

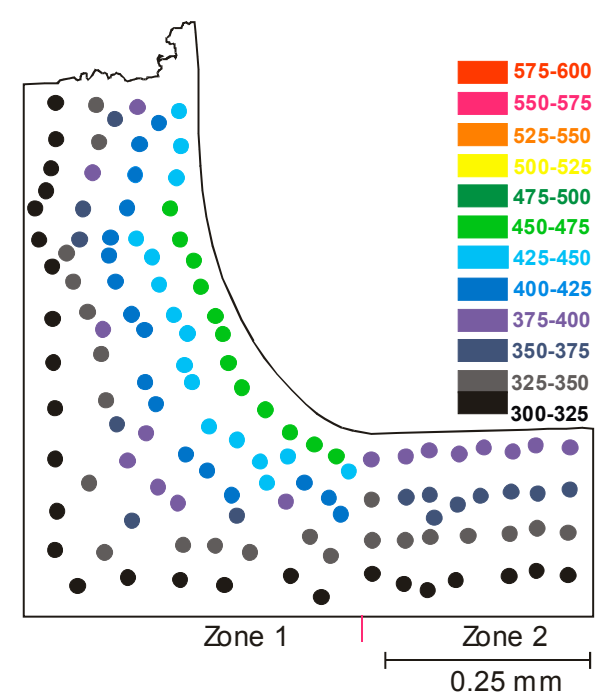

(b)

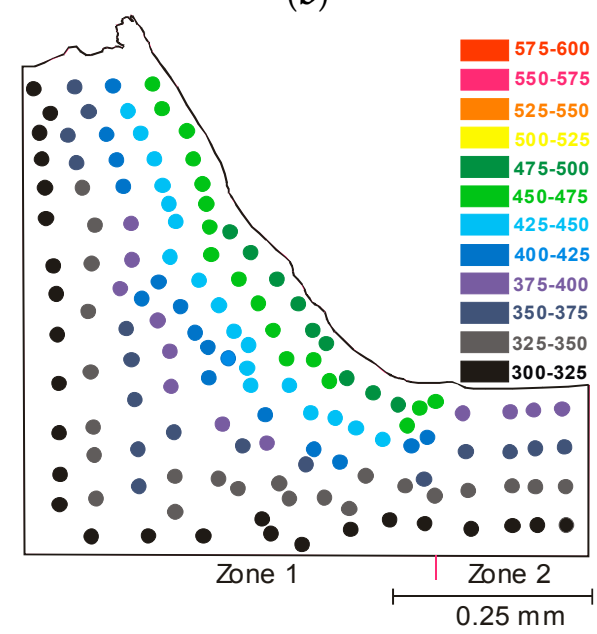

(d)

Figure 12. Microhardness (HV) maps on cross-sections of tools near milled surface: (a) Tool $\mathrm{dry}_{3}$, and (b) Tool ${ }_{\text {wet3 }}$ after the first milling pass; (c) Tool ${ }_{\mathrm{dry} 3}$, and (d) Tool ${ }_{\mathrm{we} 3}$ after the fourth milling pass, with $f_{\mathrm{t}}=0.05 \mathrm{~mm}$.

As shown in Figure 12a,b, the increase in hardness and the sizes of the work hardened zones were very similar for both the dry and wet milling, suggesting a similar shear zone size and possibly a similar thermal condition for the two different conditions. For the tools (Figure 12c,d) that were 
used for four passes (with tools heavily deteriorated) before the interruption passes, the widths of the hardened zones were slightly larger, in comparison to those when the tools were new (Figure 12a,b). However, when comparing to each other (dry and wet milling), the increase in hardness is largely the same, and the deformation zones are also comparable. The insignificant difference in the deformation zone for both the dry and wet milling has also been identified for the milling experiments using $f_{\mathrm{t}}=0.1 \mathrm{~mm} / \mathrm{rev}$, as shown in Figure 13. A greater width of $0.4 \mathrm{~mm}$ of the hardening zone and slightly higher hardness values of 475-500 HV for the higher $f_{\mathrm{t}}$ milling could be identified, because of the greater deformation for higher $f_{\mathrm{t}}$.

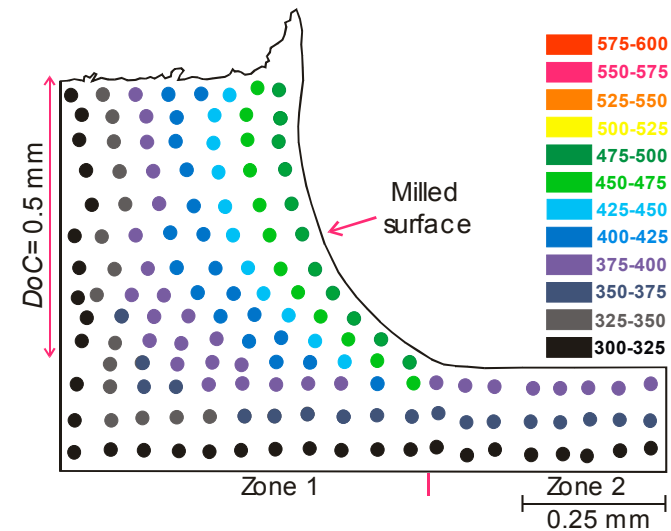

(a)

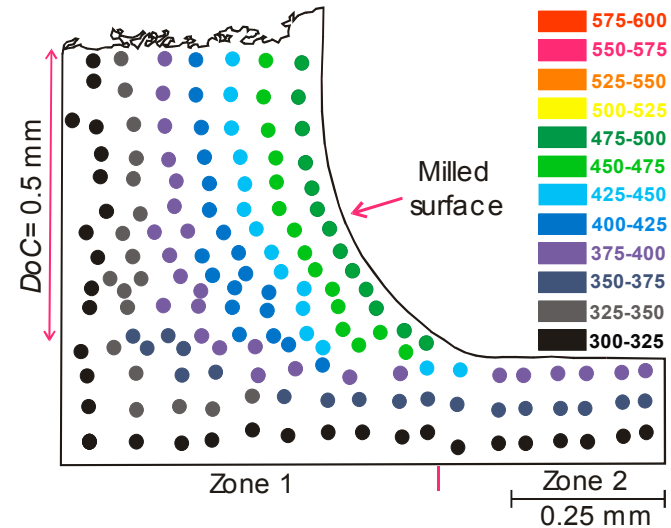

(b)

Figure 13. Microhardness (HV) maps on the cross-sections near milled surfaces of tool inserts after the first pass: (a) Tool $\mathrm{dry}_{4}$, and (b) $\operatorname{Tool}_{\mathrm{wet}}$, with $f_{\mathrm{t}}=0.1 \mathrm{~mm}$.

Considering the comparative (dry and wet milling) data in Figures 12 and 13, it may thus be suggested that the coolant must not have reached the cutting interface for cooling purposes, and the flooding of the workpiece with a coolant did not affect the thermal condition of the small cutting/deformation zone of $0.2-0.4 \mathrm{~mm}$ in width. That this cutting force did not change significantly with the use of a coolant should then have been the result of the insignificant effect of the coolant on the thermomechanical condition in the workpiece-tool contact area and cutting zone. As the cutting force did not change, it is reasonable to observe an insignificant change in the tool life. For the $f_{\mathrm{t}}=0.05 \mathrm{~mm} / \mathrm{rev}$ milling, the increase in the hardness due to hardening was up to 150-175 HV. For the $f_{\mathrm{t}}=0.1 \mathrm{~mm} / \mathrm{rev}$ milling, the increase was up to 175-200 HV. These, according to the analysis of Ren and Liu [25], represent a considerable increase in strength from <1000 to $1500 \mathrm{MPa}$. For milling in such a hardened state, for which the use of a coolant has no influence, the tool life is thus short.

\section{Conclusions}

Using cemented tungsten carbide tool inserts for milling 718Plus nickel superalloy, increasing the feed rate $\left(f_{\mathrm{t}}\right)$ from the commonly used value of 0.05 to $0.1 \mathrm{~mm} / \mathrm{rev}$ has resulted in the tool failure mode to dominantly be edge chipping. Fracturing along the flank face extending far outside the cutting edge readily occurred for $f_{\mathrm{t}}=0.05 \mathrm{~mm} / \mathrm{rev}$, and rarely occurred for $f_{\mathrm{t}}=0.1 \mathrm{~mm} / \mathrm{rev}$. The single dominant mode of tool failure in turn resulted in the milling force $(F)$ linearly increasing with the increase in flank wear $\left(V B_{\max }\right)$. This was the result of the increase in the tool-workpiece contact/cutting area proportional to the increase in $V B_{\max }$ in the case of tool deterioration confined to the cutting edge area, as edge chipping prevailed when the high $f_{\mathrm{t}}$ value was used. The use of a coolant was found to have little effect on $F$, and there was no improvement in the tool life. Hardness in the milling deformation-affected zone increased significantly, as the result of work hardening. The size of the hardened zone, up to $0.4 \mathrm{~mm}$ deep from the milled front/surface, and the magnitude of the increase in hardness were similar for both dry and wet milling. This suggests that the coolant did not reach 
the tool-workpiece cutting interface and did not affect the thermomechanical condition within the small deformation zone during milling. Thus, the use of a coolant has not improved the tool life in the present experiments.

Acknowledgments: Nurul H. Razak would like to acknowledge the partial financial support from the Universiti Malaysia Pahang (UMP). We would like to thank Rich Jeniski and Karl Lehnhardt of ATI Metals for providing the 718Plus materials. We also would like to thank Jim Crossen and Thomas Jones for assisting in all of the milling experiments.

Author Contributions: Nurul H. Razak and Zhan W. Chen planned the study. Nurul H. Razak conducted experiments and failure analysis, assisted by Zhan W. Chen. Timotius Pasang took part in the discussion of the results. Zhan W. Chen primarily drafted and Nurul H. Razak and Timotius Pasang reviewed the manuscript.

Conflicts of Interest: The authors declare no conflict of interest.

\section{References}

1. Thakur, A.; Gangopadhyay, S. State-of-the-art in surface integrity in machining of nickel-based superalloys. Int. J. Mach. Tools Manuf. 2016, 100, 25-54. [CrossRef]

2. Ulutan, D.; Pleta, A.; Henderson, A.; Mears, L. Comparison and cost optimization of solid tool life in end milling nickel-based superalloy. Procedia Manuf. 2015, 1, 522-533. [CrossRef]

3. Liu, Z.Y.; Guo, Y.B.; Sealy, M.P.; Liu, Z.Q. Energy consumption and process sustainability of hard milling with tool wear progression. J. Mater. Process. Technol. 2016, 229, 305-312. [CrossRef]

4. Zhu, D.; Zhang, X.; Ding, H. Tool wear characteristics in machining of nickel-based superalloys. Int. J. Mach. Tools Manuf. 2013, 64, 60-77. [CrossRef]

5. Pervaiz, S.; Rashid, A.; Deiab, I.; Nicolescu, M. Influence of tool materials on machinability of titanium and nickel-based alloys: A review. Mater. Manuf. Process. 2014, 29, 219-252. [CrossRef]

6. Akhtar, W.; Sun, J.; Sun, P.; Chen, W.; Saleem, Z. Tool wear mechanisms in the machining of nickel based super-alloys: A review. Front. Mech. Eng. 2014, 9, 106-119. [CrossRef]

7. Chen, X.Q.; Li, H.Z. Development of a tool wear observer model for online tool condition monitoring and control in machining nickel-based alloys. Int. J. Adv. Manuf. Technol. 2009, 45, 786-800. [CrossRef]

8. Zhang, S.; Li, J.F.; Wang, Y.W. Tool life and cutting forces in end milling Inconel 718 under dry minimum quantity cooling lubrication cutting conditions. J. Clean. Prod. 2012, 32, 81-87. [CrossRef]

9. Ucun, L.; Aslantas, K.; Bedir, F. An experimental investigation of the effect of coating material on tool wear in micro milling of Inconel 718 super alloy. Wear 2013, 300, 8-19. [CrossRef]

10. Ghani, J.A.; Haron, C.H.C. Wear mechanism of coated and uncoated carbide cutting tool in machining process. J. Mater. Res. 2016, 31, 1873-1879. [CrossRef]

11. Razak, N.H.; Chen, Z.W.; Pasang, T. Modes of tool deterioration during milling of 718Plus superalloy using cemented tungsten carbide tools. Wear 2014, 316, 92-100. [CrossRef]

12. Razak, N.H.; Chen, Z.W.; Pasang, T. Progression of tool deterioration and related cutting force during milling 718Plus superalloy using cemented tungsten carbide tools. Int. J. Adv. Manuf. Technol. 2016, 86, 3203-3216. [CrossRef]

13. Li, H.Z.; Zeng, H.; Chen, X.Q. An experimental study of tool wear and cutting force variation in the end milling of Inconel 718 with coated carbide inserts. J. Mater. Process. Technol. 2006, 18, 296-304. [CrossRef]

14. Kadirgama, K.; Abou-El-Hossein, K.A.; Noor, M.M.; Sharma, K.V.; Mohammad, B. Tool life and wear mechanism when machining Hastelloy C-22HS. Wear 2011, 270, 258-268. [CrossRef]

15. Henderson, A.J. Updated Force Model for Milling Nickel-Based Superalloys. Ph.D. Thesis, Clemson University, Clemson, SC, USA, 2012.

16. Kasim, M.S.; Che Haron, C.H.; Ghani, J.A.; Sulaiman, M.A.; Yazid, M.Z.A. Wear mechanism and notch wear location prediction model in ball nose end milling of Inconel 718. Wear 2013, 302, 1171-1179. [CrossRef]

17. Nath, C.; Brooks, Z.; Kurfess, T.R. Machinability study and process optimization in face milling of some super alloys with indexable copy face mill inserts. J. Manuf. Process. 2015, 20, 88-97. [CrossRef]

18. Hadi, M.A.; Ghani, J.A.; Haron, C.H.C. Effect of cutting speed on the carbide cutting tool in milling Inconel 718 alloy. J. Mater. Res. 2016, 31, 1885-1892. [CrossRef]

19. Rodrigues, M.A.; Hassui, A.; da Silva, R.H.L. Tool life and wear mechanisms during alloy 625 face milling. Int. J. Adv. Manuf. Technol. 2016, 85, 1439-1448. [CrossRef] 
20. ISO Standard 3002/4; International Organisation for Stardardization: Geneva, Switzerland, 1984.

21. ISO Standard 8688-2; International Organisation for Stardardization: Geneva, Switzerland, 1989.

22. Kaya, B.; Oysu, C.; Ertunc, H.M. Force-torque based on-line tool wear estimation system for CNC milling of Inconel 718 using neural networks. Adv. Eng. Softw. 2011, 42, 76-84. [CrossRef]

23. Nouri, M.; Fussell, B.K.; Zinit, B.L.; Linder, E. Real-time tool wear monitoring in milling using a cutting condition independent method. Int. J. Mach. Tools Manuf. 2015, 89, 1-13. [CrossRef]

24. Shokrani, A.; Dhokia, V.; Newnan, S.T. Environmentally conscious machining of difficult-to-machine materials with regard to cutting fluids. Int. J. Mach. Tools Manuf. 2012, 57, 83-101. [CrossRef]

25. Ren, X.; Liu, Z. Influence of cutting parameters on work hardening behaviour of surface layer during turning superalloy Inconel 718. Int. J. Adv. Manuf. Technol. 2016, 85, 2319-2327. [CrossRef]

(C) 2017 by the authors. Licensee MDPI, Basel, Switzerland. This article is an open access article distributed under the terms and conditions of the Creative Commons Attribution (CC BY) license (http:// creativecommons.org/licenses/by/4.0/). 